\title{
A Thermodynamic Study of Methane Hydrates Formation In Glass Beads
}

Tintin Mutiara *,1,2

Budhijanto ${ }^{1}$

I Made Bendiyasa ${ }^{1}$

Imam Prasetya ${ }^{1}$

1 Department of Chemical Engineering, Gadjah Mada University, Jl. Grafika No.2, Yogyakarta, Indonesia 55281

2 Department of Chemical Engineering, Islamic University of Indonesia, Jl. Kaliurang Km.14.5 Yogyakarta, Indonesia 55584

*e-mail: tintin.mutiara@uii.ac.id

Natural gas hydrates are non-stoichiometry compounds, in which the molecules of gas are trapped in crystalline cells consisting of water molecules retained by energy of hydrogen bonds. The experiments of Methane hydrate formation are performed at constant temperature in a reactor filled with various sizes of glass beads and water. Methane gas was fed into the reactor at various initial pressures. Equilibrium condition was reached when the system pressure did not change. The experimental results showed that the size of the glass beads gave very small effect on the equilibrium pressure of methane hydrate formation, so the effect could be neglected. In this study, the equation of Langmuir constant was $\mathrm{C}_{\mathrm{i}, \mathrm{CH} 4}=\frac{1}{\mathrm{RT}} \exp \left[\mathrm{A}+\frac{\mathrm{B}}{\mathrm{T}}\right]$ with the values of $\mathrm{A}$ and $\mathrm{B}$ for small cages were 6.8465 and 18.0342 . The values of $A$ and $B$ for large cages were 7.7598 and 18.0361.

Keywords: equilibrium, thermodynamic, methane hydrates, glass beads

\section{INTRODUCTION}

Natural gas hydrates are crystalline solids composed of water and natural gas. The gas molecules (guests) are trapped in water cages that are composed of hydrogen-bonded water molecules. Typical natural gas molecules include methane, ethane, propane, and carbon dioxide (Sloan 2008). Natural gas deposit in the form of hydrates exceeds $1.5 \times 10^{16}$ $\mathrm{m}^{3}$. Commercial production $15 \%$ of the natural gas hydrate deposit would provide the world's energy for 200 years at the current level of energy (Makogon 2007).

Hydrates are classified by the arrangement of the water molecules in the crystal, and the crystal structure. Two common types of hydrates are type I and type II, which sometimes referred to as structure I and II. The third type of hydrate that also may be encountered is type $\mathrm{H}$ (also known as structure $\mathrm{H}$ ), but this type is less common. One of the reasons why it took a long time to establish the crystal structure of hydrates is because hydrates 
Table 1. Geometry structure of hydrate I, II and H (Carroll 2009)

\begin{tabular}{lccc}
\hline & Structure I & Structure II & Structure H \\
\hline No. of water molecule per unit cell & 46 & 136 & 34 \\
\hline Small cavity per unit cell & 2 & 16 & 3 \\
\hline Medium cavity per unit cell & - & - & 2 \\
\hline Large cavity per unit cell & 6 & 8 & 1 \\
\hline
\end{tabular}

are non-stoichiometric. A stable hydrate can form without a guest molecule occupying all of the cages. The degree of saturation is a function of the temperature and pressure (Carroll 2009).

If all of the cages are filled by methane gas, a cubic meter solid hydrates contain $170.7 \mathrm{~m}^{3}$ methane gas in standard room temperature and pressure. In the nature, a meter cubic of hydrates contains up to 164 $\mathrm{m}^{3}$ methane gas (Thomas 2004).

In this study, we used glass beads to imitate natural sediment as the media to form methane hydrates. As we know in deep ocean, methane hydrates are formed in sediment layers. Glass beads become one of many choices to imitate natural sediment, because silica is the main compound in natural sediment. Jung and Carlos Santamarina (2012) studied the silica effect on hydrates formation. They stated that hydrates growth was affected by surface of the sediment. Hydrates growth on glass surface is faster than its growth on glass layered with oil. Liang et al. (2011) stated that silica is facilitating crystal growth near the surface area.

\section{THERMODYNAMIC MODEL}

This experiment is adopted thermodynamic modeling of hydrates gas formation by Van der Waals and Platteeuw (1959). They developed equilibrium model of hydrate cages formation by water and gas molecules enter to water cages which resembles Langmuir's gas adsorption model. In the model, it was assumed that :

a. Each water cage was filled with one gas molecule in maximum.

b. No interaction between gas molecule and water cage.

c. Partition function of ideal gas was applied to guest molecules

Phase equilibrium hydrate lattice from liquid water to hydrate could be written follows:

$$
\begin{aligned}
\Delta \mu_{\mathrm{w}}^{\mathrm{H}} & =\mu_{\mathrm{w}}^{\beta}-\mu_{\mathrm{w}}^{\mathrm{H}}=\mu_{\mathrm{w}}^{\beta}-\mu_{\mathrm{w}}^{\mathrm{L}} \\
& =\Delta \mu_{\mathrm{w}}^{\mathrm{L}}
\end{aligned}
$$


where $\mu^{H} w$ is the chemical potential of water in hydrate phase, $\mu^{L} w$ is the chemical potential of water in liquid phase, and $\mu^{\beta} w$ is the chemical potential of water in the hypothetical empty hydrate lattice at the same temperature and pressure.

$\Delta \mu^{H} \mathrm{w}$ is calculated from the statistical mechanics model proposed by Van der Waals and Platteeuw (1959),

$\Delta \mu_{\mathrm{w}}^{\mathrm{H}}(\mathrm{T}, \mathrm{P})=-\mathrm{RT} \sum_{\mathrm{i}=1}^{2} \mathrm{v}_{\mathrm{i}} \ln \left(1-\sum_{\mathrm{j}=1}^{\mathrm{Nc}} \theta_{\mathrm{ij}}\right)$

where $v_{i}$ is the number of i-type cages (also called "cavities") per water. For hydrate type $I$, the number of small cavities $\mathrm{v}_{1}$ equal to $1 / 23$, and large cavities $v_{2}$ are $3 / 23$. Nc is the number of gas components. $\Theta_{i, j}$ is the fractional occupancy of i-type cavities with j-type guest molecules.

$\theta_{i, j}=\frac{C_{i, j} f_{j}}{1+C_{i, j} f_{j}}$

where $f_{\mathrm{j}}$ is fugacity of gas $\mathrm{j}$ and $\mathrm{C}_{\mathrm{i}, \mathrm{j}}$ is the temperature-dependent Langmuir constant of gas component $\mathrm{j}$ in i-type cavity. $C_{i, j}$ depends on potential function between molecules and is defined as :

$\mathrm{C}_{\mathrm{ij}}=\frac{1}{\mathrm{RT}} \iint \exp \left[-\frac{\mathrm{W}(\mathrm{r}, \Omega)}{\mathrm{kT}}\right] \mathrm{drd} \Omega$

where $r$ is the radial vector of the guest molecule from the center of the cavity, $\Omega$ is the orientation vector of the guest molecule in the cavity, and $\mathrm{k}$ is Boltzmann constant (Duan 2011). $\Delta \mu^{\mathrm{L}} \mathrm{w}$ is calculated from the expression proposed by Holder et al. (1980)

$$
\begin{aligned}
\frac{\Delta \mu_{\mathrm{w}}^{\mathrm{L}}(\mathrm{T}, \mathrm{P})}{\mathrm{RT}}= & \frac{\Delta \mu_{\mathrm{w}}^{0}(\mathrm{~T} 0,0)}{\mathrm{RT} 0}-\int_{\mathrm{T} 0}^{\mathrm{T}}\left(\frac{\Delta \mathrm{h}_{\mathrm{w}}^{\beta-\mathrm{L}}}{\mathrm{RT}^{2}}\right) \mathrm{dT} \\
& +\int_{0}^{\mathrm{P}}\left(\frac{\Delta \mathrm{V}_{\mathrm{w}}^{\beta-\mathrm{L}}}{\mathrm{RT}}\right) \mathrm{dP}-\ln \mathrm{a}_{\mathrm{w}} \\
\Delta \mathrm{h}_{\mathrm{w}}^{\beta-\mathrm{L}}= & \Delta \mathrm{h}_{\mathrm{w}}^{0}(\mathrm{~T} 0)+\Delta \mathrm{h}_{\mathrm{w}}^{\alpha-\mathrm{L}}+\int_{\mathrm{T} 0}^{\mathrm{T}} \Delta \mathrm{CpdT}
\end{aligned}
$$

The value of $\Delta \mu^{0} \mathrm{w}, \Delta \mathrm{h}^{0} \mathrm{w}$, and $\Delta C p$ for hydrate type I can be seen on Table 2. $a_{w}$ is water activity, $\Delta \mathrm{h}^{\beta-\mathrm{L}} \mathrm{W}$ and $\Delta \mathrm{V}^{\beta-\mathrm{L}} \mathrm{W}$ are difference of enthalpy and the molar volume between hydrate and liquid water. Water molar volume in empty hydrate phase is calculated by the following formula:

$$
\begin{gathered}
V_{w}^{\beta}(T, P)=\left(11.820+2.217 \times 10^{-5} T\right. \\
\left.+2.242 \times 10^{-6} T^{2}\right)^{3} \\
\frac{10^{-30} N_{A}}{N_{w}^{\beta}} \times \exp \left(-3.5 \times 10^{-4}(P-0.1)\right. \\
\left.+7.07 \times 10^{-6}(P-0.1)^{1.5}\right)
\end{gathered}
$$

where $N_{A}$ is Avogadro's number, $N^{\beta} W$ is the number of water molecules per hydrate cell. For hydrate type $\mathrm{I}, \mathrm{N}^{\beta} \mathrm{W}$ is 46 . In equation (7) the unit for pressure is $\mathrm{MPa}$ and temperature is $\mathrm{K}$ (Duan 2007).

Table 2. Thermodynamic Properties of Hydrate Structure I, To $=273,15 \mathrm{~K}$ (Duan, 2007)

\begin{tabular}{ll}
\hline Properties & Value \\
\hline$\Delta \mu^{0} \mathrm{w}(\mathrm{J} / \mathrm{mole})$ & 1202 \\
\hline$\Delta \mathrm{h}^{0} \mathrm{w}(\mathrm{J} / \mathrm{mole})$ & 1300 \\
\hline$\Delta \mathrm{h}^{\alpha-\mathrm{L}} \mathrm{W}(\mathrm{J} / \mathrm{mole})$ & -6009.5 \\
\hline$\Delta C \mathrm{p}^{\beta-\mathrm{L}}(\mathrm{J} / \mathrm{mole} / \mathrm{K})$ & $-38.12+0.141 \times(\mathrm{T}-\mathrm{To})$ \\
\hline$\Delta C \mathrm{p}^{\beta-\alpha}(\mathrm{J} / \mathrm{mole} / \mathrm{K})$ & $0.565+0.002 \times(\mathrm{T}-\mathrm{To})$ \\
\hline
\end{tabular}




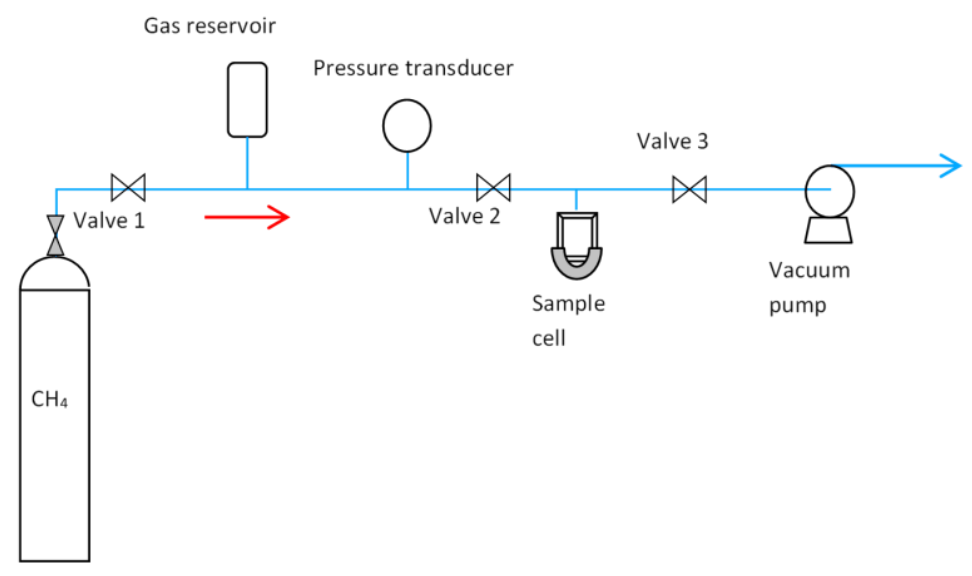

Fig. 1: Experiment Apparatus

Table 3. Hydrate formation conditions

\begin{tabular}{cccc}
\hline \multirow{2}{*}{ Temperature (K) } & \multicolumn{3}{c}{ Pressure } \\
\cline { 2 - 4 } & Beads 250 $\mathbf{\mu m}$ & Beads 425 $\mathbf{\mu m}$ & Beads 680 $\boldsymbol{\mu m}$ \\
\hline 274 & 27.90 & 27.85 & 27.83 \\
\hline 274.5 & 30.44 & 29.87 & 30.41 \\
\hline 275 & 32.08 & 32.04 & 31.91 \\
\hline 275.5 & 33.95 & 33.86 & 32.86 \\
\hline 276 & 35.20 & 35.13 & 35.08 \\
\hline
\end{tabular}

\section{EXPERIMENTAL}

Experiment apparatus can be seen on Figure 1. Glass beads were filled in the reactor, then demineralized water added with weight ratio of water to glass beads is $1.5: 6$. The experiments were conducted isothermally at various temperatures 274 K, 274,5 K, $275 \mathrm{~K}, 275.5 \mathrm{~K}$, and $276 \mathrm{~K}$. Methane gas was injected into the system at various initial pressures. No change in the system pressure indicated that the equilibrium was reached.

\section{RESULTS AND DISCUSSION}

This thermodynamic study of methane hydrates formation in glass beads consists of two steps. First is to determinate equilibrium pressure of hydrates formation at various temperatures and glass beads size, and second is to calculate Langmuir's constant $\left(C_{i, j}\right)$ with Van der Waals Platteeuw model as the main variable to predict cage occupancy and gas hydrates phase equilibrium.

Temperature affected the pressure of methane hydrates formation. The higher temperature, the higher pressure of methane hydrates formation, as seen on Table 3. When the size of glass beads were smaller, the pressure of methane hydrates formation were higher. This trend was not observed at $274.5 \mathrm{~K}$, possibly due to the experiment error. These result are in agreement with the study held by Kang Seong-Pil et al. (2007), with conclusion 
that three phase equilibrium curve (hydrate-liquid-vapor $\mathrm{H}-\mathrm{L}-\mathrm{V}$ ) in porous moved to higher pressure if compared to bulk system, this study didn't contradict.

To predict methane hydrate equilibrium in glass beads, a model developed by Van der Waals and Platteeuw (1959) is used. With an innovation in determination of the Langmuir's constant $\left(C_{i, j}\right)$. The definition of Langmuir's constant as shown in Equation (4).

$\mathrm{C}_{\mathrm{ij}}=\frac{1}{\mathrm{RT}} \iint \exp \left[-\frac{\mathrm{W}(\mathrm{r}, \Omega)}{\mathrm{kT}}\right] \mathrm{drd} \Omega$

where $r$ and $\Omega$ are vector position and vector orientation gas molecule $\mathrm{j}$, while $\mathrm{k}$ is Boltzmann's constant. This formula is simplified into the following form:

$C_{i, j}=\frac{1}{R T} \exp \left[A+\frac{B}{T}\right]$

Statistical test was conducted to determine the effect of glass beads' size to Langmuir's constant and hydrates formation equilibrium. The result of statistical test indicated that the Langmuir's constant does not change significantly with the variation of glass bead size. So it can be concluded that the value of the Langmuir's constant are the same at various glass beads' size. The average value of Langmuir's constant for glass beads sizes 250,425 and $680 \mu \mathrm{m}$ is:

$$
\begin{aligned}
& \mathrm{C}_{1, \mathrm{CH} 4}=\frac{1}{\mathrm{RT}} \exp \left[6,8465+\frac{18,0342}{\mathrm{~T}}\right] \\
& \mathrm{C}_{2, \mathrm{CH} 4}=\frac{1}{\mathrm{RT}} \exp \left[7,7598+\frac{18,0361}{\mathrm{~T}}\right]
\end{aligned}
$$

After the Langmuir's constant of methane hydrates formation was obtained, the calculation of the equilibrium conditions of methane hydrates formation can be completed. Finally the value of equilibrium pressure and temperature of methane hydrates formation were obtained using Van der Waals - Platteeuw model. In Figure 2, the value of pressure and temperature of

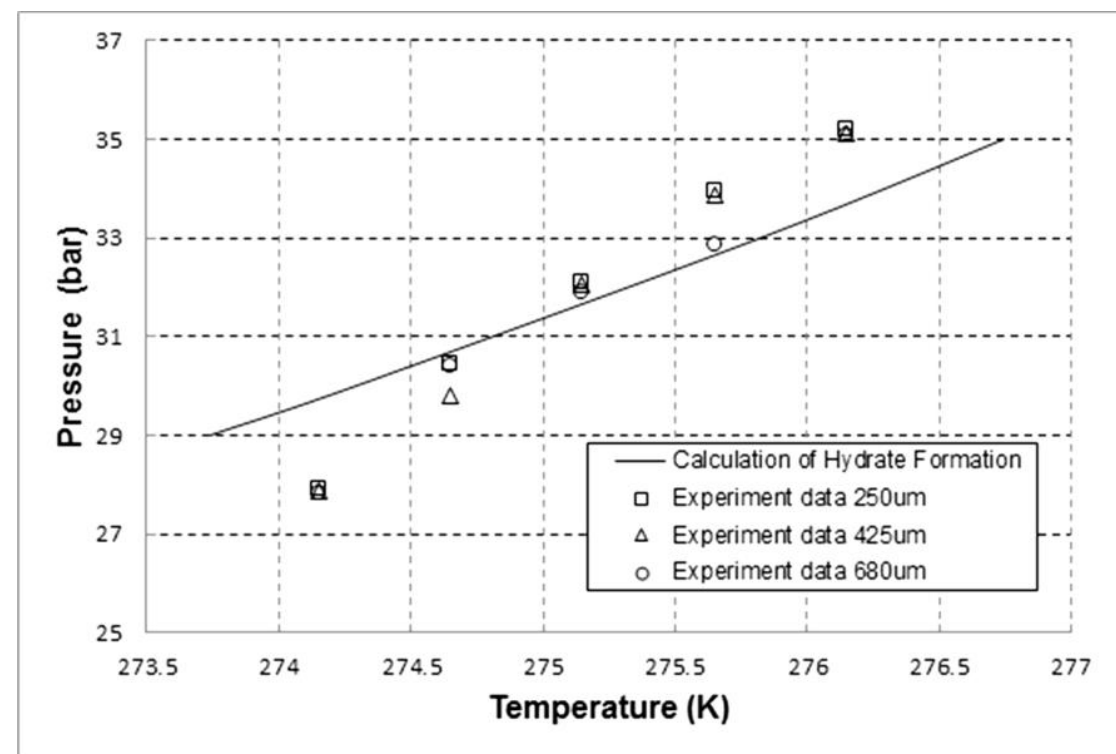

Fig. 2: Hydrate formation conditions. 
Table 4. Hydrate cage occupancy by methane molecules

\begin{tabular}{cccc}
\hline T (K) & This experiment & Cao et al. & Klauda and Sandler \\
\hline \multicolumn{5}{c}{ Small cage } \\
\hline 274.65 & 0.8297 & 0.961 & 0.748 \\
\hline 275.65 & 0.8795 & 0.964 & 0.758 \\
\hline 276.65 & 0.9339 & 0.965 & 0.768 \\
\hline \multicolumn{5}{c}{ Large cage } \\
\hline 274.65 & 0.8639 & 0.957 & 0.945 \\
\hline 275.65 & 0.9158 & 0.961 & 0.947 \\
\hline 276.65 & 0.9724 & 0.963 & 0.950 \\
\hline
\end{tabular}

methane hydrates formation from calculation were compared with experimental data.

As seen on Figure 2, the calculated data were close enough to the experimental data. Thus the model was good enough to predict data around research data ranges, but for extrapolation, this model needs further improvement. This model assumes that, hydrate cages were first formed and then gas molecules adsorbed into the cages. Yet in reality, gas molecules were dissolved into liquid phase then hydrate cages were formed around the gas molecules.

Langmuir's constant data can be used to predict the fraction of cage occupancy by gas molecules. Table 4 presents the comparison between data of fraction of cage occupancy from this study and data from the experiments by Cao. et al. (2001) and Klauda and Sandler (2002, 2003). It can be seen that the degree of cage occupancy was big enough. It indicated that the empty cages were just a few, Most cages were filled by methane gas molecules.

As seen on Table 4, the degree of occupancy of gas molecules in large cages was greater than the degree of occupancy in small cages. So it can be concluded that the methane gas molecules filled large cages more than small cages.

\section{CONCLUSIONS}

The conclusions of this experiment are as follows. The higher temperature, the higher equilibrium pressure of methane hydrate formation, the size of glass beads does not affect the equilibrium conditions of methane hydrate formation, and the Langmuir constants are not affected by the size of glass beads. In this study, the Langmuir constant values follow the following equation $\mathrm{C}_{1, \mathrm{CH} 4}=$ $\frac{1}{\mathrm{RT}} \exp \left[6,8465+\frac{18,0342}{\mathrm{~T}}\right]$ for small cages and $\mathrm{C}_{2, \mathrm{CH} 4}=\frac{1}{\mathrm{RT}} \exp \left[7,7598+\frac{18,0361}{\mathrm{~T}}\right]$ for the large cages.

\section{ACKNOWLEDGEMENT}

Acknowledgement is made to the Lembaga Penelitian dan Pengabdian kepada Masyarakat (LPPM) Gadjah Mada University, for the support of this research fund. 


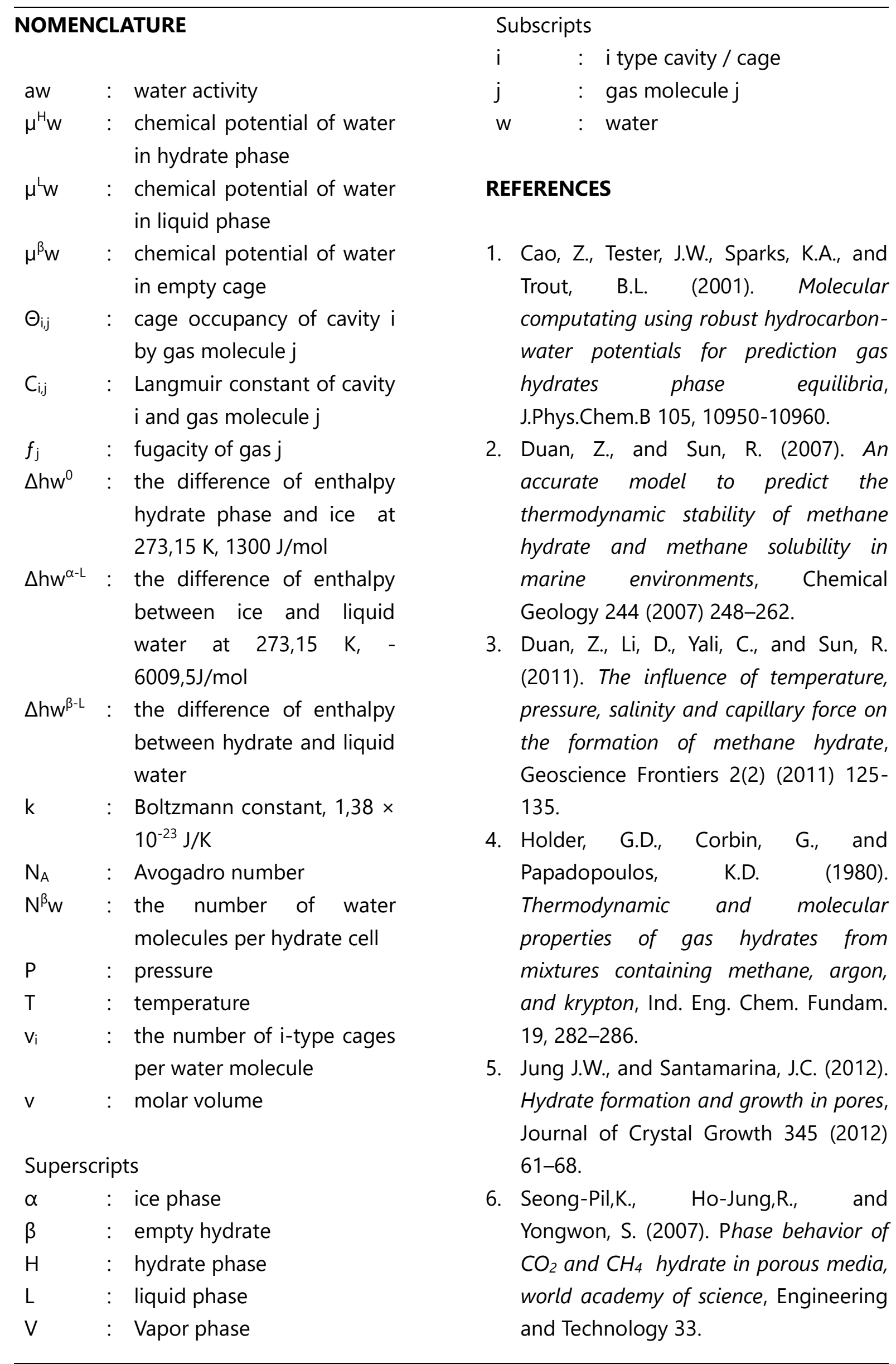


7. Klauda, J.B., and Sandler, S.I. (2002). $A b$ initio intermolecular potentials for gas hydrates and their predictions, J.Phys.Chem. B 106, 5722-5732.

8. Klauda, J.B., and Sandler, S.I., 2003, Phase Behavior of Clathrate Hydrates : A Model for Single and Multiple Gas Component Hydrates, Chem.eng.Sci. 58, 27-41.

9. Liang, S., Rozmanov, D., and Kusalik, P.G. (2011). Crystal growth simulations of methane hydrates in the presence of silica surfaces, Phys. Chem. Chem. Phys., 2011, 13, 19856-19864.
10. Makogon, Y.F., Holditch, S.A., and Makogon, T.Y. (2007). Natural gas hydrates - a potential energy source for the 21st century, Journal of Petroleum Science and Engineering.

11. Sloan E.D., and Koh C.A. (2008). Clathrate hydrates of natural gases, 3rd Ed., Taylor and Francis Group, USA.

12. Thomas, E. (2004). Clathrates: little known components of the global carbon cycle, Wesleyan University.

13. Van der Waals, J.H., and Platteeuw, J.C. (1959). Clathrate solutions, In : Prigogine, I. (Ed.), Advances in Chemical Physics. Interscience. 